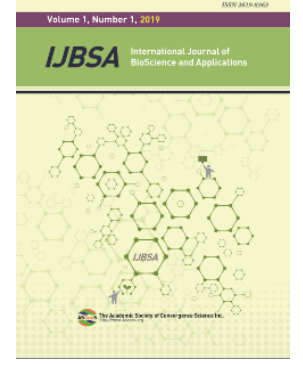

International Journal of

BioScience and Applications

\title{
A study on the Adaptation of Chinese International Students to a Nursing College at a Local University in Korea
}

\author{
Ja-Ok Kim¹, Su-hyun Kim², Yeo-Jin Kim¹, A-Young Park ${ }^{3}$, and Hack-Sun Kim* \\ ${ }^{1}$ Associate Professor, Department of Nursing, Wonkwang Health Science University, 514 Iksandae-ro Sinyong- \\ dong Iksan-si, Jeollabuk-do, 54538, Public of Korea \\ ${ }^{2}$ Assistant Professor, Department of Nursing, Nambu University, 23 Ceomdanjungang-ro, Gwangsan-gu \\ Gwangju, 62271, Public of Korea \\ ${ }^{3}$ Assistant Professor, Department of Nursing, Gwangju University ,277 Hyodeong-ro, Hyodeok-dong, Nam-gu, \\ Gwangju,61743, Public of Korea
}

\begin{abstract}
$^{1}$
Background/Objectives: This is a study related to the adaptation of Chinese international student at a local university to a nursing college for 4 years. Methods/Statistical analysis: There were a total of 6 participants, 2 male and 4 female. Their interviews were qualitatively analyzed. Findings: The main research results are as follows. Chinese international students classified the difficulties in adjusting to nursing college into three categories. First, it is difficult to study professionally in the Department of Nursing. This is a challenge for studying at university and for clinical practice in hospitals. Second, it was difficult to make Korean friends because I was not fluent in Korean and was unfamiliar with Korean culture. Third, it was difficult to relate to professors and friends while conducting non-face-to-face classes due to the COVID-19 infectious disease. Improvements/Applications: The research results provide basic data that international student from China who choose nursing can adapt well to their major subjects.
\end{abstract}

\section{Index Terms}

Nursing Education, Chinese International Student, Korean, Adaptation, COVID-19

\footnotetext{
Corresponding author : Hack-Sun Kim

hskim@wu.ac.kr

- Manuscript received April 15, 2021.

- Revised May 14, 2021 ; Accepted June 1, 2021.

- Date of publication June 30, 2021
}

(c) The Academic Society of Convergence Science Inc.

2619-8363 @ 2021 IJBSA. Personal use is permitted, but republication/redistribution requires IJBSA permission. 


\section{INTRODUCTION}

In recent years, the number of foreign students in universities is increasing, and among them, Chinese students account for a high proportion. In 2010, to strengthen the competitiveness of Global Hub College, foreign students were invited to excellent colleges in Korea, and Open Course-Ware(OCW) was expanded to strengthen the university's global research capabilities. The highest stress among Chinese international students is longing for their hometown. Culture shock due to cultural differences and stress due to difficulties in communication, feelings of isolation, and discrimination act as major sources of stress [1]. Knight argued that university internationalization is the process of integrating international and multicultural dimensions into university education, research and service functions [2]. In China, the 14th five-year-plan for 2021 specifically established plans to improve the adaptability of vocational and technical education and to improve the quality of higher education. Contents included in this plan include improvement of national standards for vocational and technical education, improvement of the quality of modern vocational and technical education, establishment of technical colleges and majors, vocational education at the undergraduate level, establishment of a diversified higher education system and optimization of higher education [3]. Along with these changes in China, Chinese students from the nursing department came to Korea.

Nursing education in Korea educates students on the ability to integrate knowledge, interpersonal skills, communication skills, and nursing interventions to practice nursing [4]. Based on these core competencies of nursing education, each university creates a nursing department curriculum and evaluates the learning outcomes that nursing students must reach for each university. Therefore, in order to carry out the curriculum of the nursing college, above all else, the ability to understand Korean is necessary. For Chinese international students, many universities are taking various measures so that they can quickly adapt to the learning environment and life. In addition, universities are exerting efforts to improve the internationalization atmosphere within universities by setting customized courses that reflect the characteristics of international students based on their educational capabilities. In particular, in order to enhance the academic efficiency and understanding of Chinese international students, a curriculum for teaching in various languages was established along with the establishment of a Chinese-centered foreigner-only department.
However, the Korean language proficiency of Chinese international students who have been studying in local nursing colleges since their first year was very poor. As for environmental factors, Corona 19 (COVID-19) occurred in Wuhan, China in December 2019 and spread to the world including Korea in January 2020. Accordingly, the World Health Organization (WHO) announced on January 30 It has declared an 'international public health emergency'[5]. As a result, the university conducted all-out non-face-to-face education.

The purpose of this study is to prepare basic data on how local Chinese international student who lack language ability showed adaptation to Korean nursing college from their first year of regular education, and what kind of social support they wanted and how they came to adapt to the university.

The specific interview topics are as follows.

1) What motivated you to choose the Department of Nursing in China?

2) What did you feel while attending the Department of Nursing in Korea?

3) What are your future plans after graduating from the Department of Nursing in Korea?

4) What helped you to graduate from the Department of Nursing in Korea?

5) What was the most difficult thing while attending the nursing department in Korea?

\section{MATERIALS AND METHOD}

\section{A. Study Design}

Research in ethnography is a compound word of 'etno', which means nation or tribe, and 'graphy', which means record and technology. Based on cultural anthropology, it is treated as a type of qualitative research in which a system of theory and methodology has been established. First, it is a research method that discovers the basis for a new theory. Second, people living in a complex modern society live through various types of cultural codes, and cultural technology provides an appropriate method to understand these complex characteristics. Third, cultural and descriptive journals can discover the meaning of an actor's behavior and have meaning as a method of analysis. The broad framework of the research design followed the cultural descriptive procedure suggested by Spradley [6,7], which is as follows. During the four years of the Department of Nursing, students were interviewed and observed as a supervisor, who basically presented the university life of Chinese international students.

Typically, cultural descriptive journals study the meaning of behavior, language, and interaction of 
cultural sharing groups through participant observation or interviews with group members [8]. In this study, a qualitative research method was selected to analyze the adaptation of Chinese international students to local nursing colleges. Qualitative research is suitable for understanding phenomena and finding problems while recording and observing people, society, and things in depth. It presupposes a description of the cultural characteristics and circumstances of a particular group [9].

\section{B. Research Process}

The data collection was intended to re-examine the adaptation of Chinese international students in nursing colleges and their own social support through a semi-structured open-ended questionnaire. In order to secure the validity of the study, triangular verification was performed between the data and between the researchers. This study was conducted with the voluntary consent of Chinese international students from the Department of Nursing. To secure the reliability of the interpretation by comparing the research results between the collected data, the analysis process was continued until consensus among the researchers was reached. In order to prevent biased interpretation through a critique process through a researcher with experience in qualitative research, peer verification of the research results was conducted by external researchers.

In this study, data collection, analysis, and interpretation were conducted. The data collected through open-ended questionnaires and interviews were analyzed using a content analysis method to categorize them by similar themes according to the inductive categorization procedure [10]. The study participants were 2 males and 4 females in total. Among them, two women constituted a structured questionnaire through the initial interview as the main information providers. The structured questionnaire was analyzed by two nursing professors who guided Chinese international students for 4 years and two nursing professors who guided Korean nursing students. In qualitative research, the researcher's theoretical sensitivity and professional and personal experience are important as a research tool in the research process, including data collection and analysis.

\section{RESULT AND DISCUSSION}

As a result of the analysis, three categories were derived as the main difficulties in adaptation: first, in terms of studying nursing, it was difficult to study professional nursing at university and adapt to clinical practice. second, from a Korean cultural point of view, the first Korean was difficult and making Korean friends was difficult. third, from an environmental point of view, it was difficult to attend non-face-to-face classes due to the outbreak of the COVID-19 infectious disease.

We would like to discuss in detail the answers to the sub-questions.

\section{1) What motivated you to choose the Department of Nursing in China?}

I have admired the profession of a nurse since childhood. When I was young, I was not feeling well, so I lived in the hospital, but the nurses were very kind and took good care of me. I have always been a nurse because when a person is ill, the love and patience of the medical staff can better understand and feel the importance of love for the patient's body and mind and the prompt discharge, and realize the deep tolerance and divinity of the angel of the white coat. dreamed of becoming (a).

I think you can get a good job(b).

A friend who likes medicine chose Korean nursing, so I did it too $(c, d)$.

The reason I chose the Department of Nursing was that I wanted to know more diseases and take good care of my family's health in the future (e).

It seems that Korean nursing departments do better than Chinese nursing departments (f).

2) What did you feel while attending the Department of Nursing in Korea?

\section{[1st year]}

When I first came to Korea, I felt unhelpful, so I felt like an outsider wherever I went, but my classmates didn't understand what I was saying, my professor couldn't answer my questions, I didn't know Korean etiquette, and I tried to blend in. I wrote it and tried to mix it again, but it seemed to collapse (a).

I'm curious about anything(b).

When I first came to Korea, it was very difficult to study because I did not speak Korean well(c).

Freshness was the biggest semester(d).

It's really hard to do anything and I didn't know anything, but thanks to the professor's help, I can get through this difficult time well(e).

When I first came, it was very difficult. At that time, I did not speak Korean well, and I did not know the school environment and school life well(f).

\section{[2 ${ }^{\text {nd }}$ year $]$}


After studying Korean for about a year, I gained communication skills, so it is difficult to study my major, but if I have a simple conversation with my friends, there will be no problems in my daily life. I go to an amusement park to relieve stress and reduce nostalgia at school. I feel good(a).

There are many classes(b).

Little by little I am adjusting to the learning environment, but it is still very difficult(c).

I switched classes and it seems like I'm an invisible person in the class(d).

There was no significant difference as in the first year(e).

When I was in 2nd year, I liked it a little more than 1st year. Because I studied Korean hard during that time. So I got to know a little bit of Korean friend in class. I also understood the contents of professional classes better than the first year(f).

\section{[3rd year]}

When I started practicing at the hospital, I was really scared, I didn't think I could do it, I didn't think I could do it, it burdened my teammates, and I was afraid of being scolded by my professor. I have to prepare for the practice test a week earlier, but I'm worried that I won't be able to get a scholarship because of my poor grades. However, in communication with patients, alumni, and professors, my speech increased and improved, and my listening skills improved compared to a year ago(a).

It is difficult to combine the 3rd grade practice and class at the same time(b).

Practice is hard(c).

I struggled with practice(d).

Through practice at the hospital, I was able to gradually improve my Korean language skills, understand the basic needs of patients who can hear, and gain more experience through practice while meeting other patients during the practice session(e).

It feels so good to have two Korean friends. I also speak Korean better than before. Professional class content can be understood when lectured in the professor's classroom. I don't think it will be as difficult as before. I feel a little more comfortable. When I talk with my Korean friends, I feel a little more at ease. I'm not afraid to talk to Koreans like I used to $(f)$.

\section{[4th grade]}

An epidemic came to school and I conducted Internet classes for almost a year, but the effect of the Internet classes was not as good as the school classes. This year, I want to communicate normally with my friends and understand everything I say to my students. I want to spend a year in the dormitory so that I can know exactly what my future path will be(a).

It was difficult because face-to-face classes were not conducted due to the outbreak of an infectious disease(b).

Due to the epidemic, I have been giving lectures online, and I am not good at it because I am a foreign student(c).

Due to the epidemic, there is a lot of homework(d).

It's a pity that I couldn't meet the professor properly due to the outbreak of an infectious disease(e).

I can't go to school this year because of COVID19, and I can't meet my Korean friends and professors, so it's a pity. Also, I couldn't practice my Korean speaking. Originally, I plan to come to Korea this semester and use my spare time after school to work part-time(f).

3) What are your future plans after graduating from the Department of Nursing in Korea?

I want to go to graduate school and continue studying nursing (a).

I want to stay and work in Korea, but it seems difficult (b).

As the COVID-19 infectious disease has spread throughout the world, he will return to Korea and enter graduate school when the situation stabilizes. I would like to help you when you go to graduate school from your current university (c).

I have no idea (d).

After returning to China, I plan to take the exam and get a license to get a job (e).

I want to go back to China and prepare for a Chinese civil service exam or a teacher exam, and then come back to Korea and enter graduate school when there is no COVID-19 (f).

4) What helped you to graduate from the Department of Nursing in Korea?

Improvement of Korean language skills, help from Korean friends, interesting teaching methods of professors, scholarship system, interest in nursing.

\section{5) What was the most difficult thing while attending the nursing department in Korea?}

Nursing class is difficult. The registration fee is expensive. Unable to understand major knowledge I couldn't remember the terminology because I didn't understand it. Hospital practice was difficult. It was difficult to do the homework in class and practice. It was difficult to make Korean friends every year. 


\section{Conclusion}

Chinese international student who came to study in Korea University of Nursing took their first steps with hope and excitement for Korean nursing. A particularly problematic problem for Chinese international student at provincial universities is that they are not fluent in Korean, even at universities in Seoul. Universities in the Seoul area can choose better Chinese international student due to the university's reputation. However, there are fewer options at local junior colleges. Nursing also includes medical terminology that Korean students find difficult. When researcher called her name, she only responded and there was no communication. In Chinese international students freshman year, they studied Korean at the university's Office of International Affairs, and in the Department of Nursing, Chinese international student studied liberal arts subjects necessary for Nursing. As Chinese international student entered their second year, Chinese international student studied full-time nursing, just like basic nursing, and expressed difficulties in their major in nursing. Researcher made a team with a Korean student, practiced reading Korean, and ordered them to eat together, which is the essence of Korea. And above all, the professor did not give up and devoted all his heart to the students who came to study in China. They showed interest by going to Daehak-ro, eating law together, shopping together, and spending time together buying clothes. Researcher also tried to practice using coupons at restaurants while sending coupons through Kakao Talk. In this way, one by one, they were able to adapt to the Korean university student culture step by step.

When they third year, Chinese international student went to clinical practice, but Chinese international student was not fluent in Korean, and it was even more difficult because Chinese international student was voted as a foreign student at the hospital. As Chinese international student practiced in an unfamiliar hospital, Chinese international student fear was even greater. In this situation, the professor directly identified the students who were conducting hospital internships with the Chinese international student as a team and asked the Korean students of the Department of Nursing for help while understanding the difficult situation of the Chinese international student. In the 4th year, Chinese international student confirmed what Chinese international student plans were for the future in Korea and made preparations for it. Chinse international student wanted to go to graduate school. So, Chinese international student decided to find a graduate school on my own. Department of Nursing
International students from China graduated from nursing school but do not have a nurse's license, so admission to the nursing department's graduate school is suggested. Also, a high TOPIK score on the Korean Proficiency Test is essential for admission to graduate school. It is necessary to recognize this situation first and to maximize the score of the Korean language proficiency test. In Korean graduate schools, scholarships are awarded according to TOPIK scores. Despite the global COVID-19 pandemic, many Chinese students are visiting Korea. This is an area that requires more consideration for Chinese international student during non-face-to-face classes.

Nursing students from China came to Korea thinking that the most important thing was that Korean nursing was excellent. However, when graduating from the Department of Nursing, the situation of international students in China was very different from when they first entered the country. The academic development of Korea's excellent nursing studies today is the result of going to the United States to acquire excellent nursing education and returning home to establish advanced nursing education in the United States as nursing education in Korea, and to make efforts for excellent professional nursing education to take root. Therefore, nursing education in Korea is growing together with nursing in the United States. In the end, Researcher thinks that it is a great achievement for the development of nursing education in Korea if Chinese students in the Department of Nursing can return to China after receiving Korea's advanced nursing education well. For this purpose, it is necessary for Korean universities to analyze various current conditions and supplement systems and policies.

Anyone who goes to a new place is afraid. In that new place, I find someone who can help me, but the most important people to the Chinese students in the Department of Nursing were the professors in the Department of Nursing and Korean friends in the Department of Nursing. Nursing is a deep love for humanity. Department of Nursing We hope that international students from China will learn the true meaning of nursing and practice meaningful Korean nursing in China.

In the future, Chinese students will be admitted to Korean universities to learn a variety of subjects. It is thought that the first step of humanity for them is to establish a curriculum suitable for Chinese international students so that they can learn the subjects they want. In future research, research on the curriculum of the nursing department for Chinese international students and textbooks for Chinese international students in the department of nursing is suggested. 


\section{REFERENCES}

[1] Lim, C. H. (2009). Stress and Adaptation of Chinese Students in College Life Culture. Korean Journal of Life Science, 18 (1), 93-112.

[2] Knight, J. (2004). Internationalization remodeled: definition, approaches and rationales, Journal of studies in international education, 8, 5-31.

[3] Xinhua News Agency. (2021). The Fourteenth Five-Year Plan for the National Economic and Social Development of the People's Republic of China and the Outline of the Longterm Goals for 2035. (Onlne). Retrieved from http://www.gov.cn/xinwen/2021 03/13/content 5592681.htm

[4] Pijl-Zieber, E. M., Barton, S., Konkin, J., Awosoga, O., Caine, V. (2014). Competence and competency-based nursing education: Finding our way through the issues, Nurse Education Today, 34(5), 676-678.

[5] WHO. (2020). WHO, The declaration COVID 19 'pandenic. 2020-04-12, Retrieved from https://m.medigatenews.com/news/3323472469. 2021.04.12.

[6] Spradley, J. P. (1979). The ethnographic interview. New York : Holt,R.,\& Winston.

[7] Spradley, J. P. (1980). Participant observation. New York : Holt,Rienhart\& Winston.

[8] Creswell, J. W. (1998). Qualitative Inquiry and Research Design. Sage.

[9] Creswell, J. W. (2007). Qualitative inquiry \& research design: Choosing among five approaches (2nd ed.). Thousand Oaks, CA:Sage

[10] Miles, M. B., Huberman, A. M., Huberman, M. A., \& Huberman, M. (1994). Qualitative data analysis: An expanded source book. Sage. 